\title{
Synthesis, Characterization and Performance of Low-Cost Unconventional Adsorbents Derived from Waste Materials
}

\author{
Sunil Kulkarni ${ }^{1, * \text { iD }}$ \\ 1 Gharda Institute of Technology, Lavel. Maharashtra, India \\ * Correspondence: suniljayantkulkarni@gmail.com;
}

Scopus Author ID 57209247314

Received: 11.04.2020; Revised: 30.05.2020; Accepted: 2.06.2020; Published: 7.06.2020

\begin{abstract}
Adsorption of the solute on solid is an equilibrium operation. The nature of adsorbent affects the efficiency of the operation. High surface area per unit volume is the essential attribute of a good adsorbent. Isotherm and kinetic studies are carried out to understand the adsorption mechanism. Many investigators have carried out batch experiments to study the effect of various parameters like initial adsorbate concentration, $\mathrm{pH}$, particle size, and adsorbent dose. The use of adsorbents derived from lowcost materials makes this operation acceptable in industries. Regeneration of adsorbent can reduce the problem of disposal of used adsorbent material. Optimum values of affecting parameters can be determined from batch experiments. The isotherm and kinetic constants can be determined from batch experiments. These investigations give us an idea about the nature of adsorbent, maximum adsorption capacity, the order of adsorption, and optimum $\mathrm{pH}$. This review sheds light on investigations on adsorbents derived from unconventional adsorbents and their characterization and performance evaluation.
\end{abstract}

Keywords: Kinetic; isotherm; pH; concentration; active sites; surface area; size.

(C) 2020 by the authors. This article is an open-access article distributed under the terms and conditions of the Creative Commons Attribution (CC BY) license (https://creativecommons.org/licenses/by/4.0/).

\section{Introduction}

Adsorption involves mass transfer from the fluid to solid. Certain solids have the ability to concentrate certain substances on their surfaces [1].

Removal of impurities from liquid and gaseous effluent is one of the significant applications of adsorption. The solid must possess certain physical and chemical properties if it is to be used as an adsorbent. Large surface area per unit weight is the most important criterion in the selection of adsorbent. Silica gel, activated carbon, Fuller's earth, Alumina, clays are examples of conventional adsorbents. Adsorption equilibria is a relation between the adsorbed solute concentration and concentration in the fluid at equilibrium.

Freundlich and Langmuir's isotherms are used to explain the equilibrium at isothermal conditions. First and second-order kinetic models are to describe adsorption kinetics.

\section{Isotherms and Equilibria}

\subsection{Isotherms.}

Freundlich isotherm equation is represented as [1],

$$
\mathrm{C}^{*}=\mathrm{k}\left[\mathrm{v}\left(\mathrm{C}_{0}-\mathrm{C}^{*}\right)\right]^{\mathrm{n}}[1]
$$


$\mathrm{v}\left(\mathrm{C}_{0}-\mathrm{C}^{*}\right)$ is apparent adsorption per unit mass of adsorbent, $\mathrm{k}$, and $\mathrm{n}$ are constants. $\mathrm{C}_{\mathrm{o}}$ and $\mathrm{C}$ are initial and, at any time, $\mathrm{t}$, concentrations of the solution. $\mathrm{C}^{*}$ is the concentration at equilibrium.

Alternatively [2-5],

$$
\mathrm{X} / \mathrm{M}=\mathrm{k} \mathrm{C}^{1 / \mathrm{n}} \quad[2]
$$

$\mathrm{X} / \mathrm{M}$ is apparent adsorption per unit mass of adsorbent, $\mathrm{k}$, and $\mathrm{n}$ are constants.

Langmuir isotherm is expressed as [4-6]

$$
\mathrm{q}_{\mathrm{e}}=\frac{q 0 b C e}{(1+b C e)}[3]
$$

where

$q_{e}=$ equilibrium adsorbent-phase concentration of adsorbate $(\mathrm{mg} / \mathrm{L})$

$C_{e}=$ equilibrium aqueous-phase concentration of adsorbate $(\mathrm{mg} / \mathrm{L})$

$Q^{0}$ is the monolayer adsorption capacity $(\mathrm{mg} / \mathrm{g})$

$b$ is the constant related to the free adsorption energy and the reciprocal of the concentration at which half-saturation of the adsorbent is reached.

These equations are linear in their logarithmic forms. These isotherm equations can be plotted on the logarithmic scale or taking their logarithms to examine their linearity. If the graph is linear with $\mathrm{R}^{2}$ values near 0.99 , the isotherm is validated.

\subsection{Kinetics.}

Adsorption kinetics of the fluid-solid system must be understood before its application. The kinetics models explain the mechanism of adsorption. Pseudo first order and pseudosecond-order kinetic models are used to explain the kinetics of adsorption. These models are expressed as the following equations [7-11].

$$
\ln \left(q_{e}-q_{t}\right)=\ln q_{e}-k_{1} \mathrm{t}(5)
$$

Where $\mathrm{q}_{\mathrm{e}}(\mathrm{X} / \mathrm{M})$ is the mass of metal ion adsorbed at equilibrium $(\mathrm{mg} / \mathrm{g}), \mathrm{q}_{\mathrm{t}}$ is the mass of metal adsorbed at time $\mathrm{t}(\mathrm{mg} / \mathrm{g}), \mathrm{k}_{1}$ is the first-order reaction rate constant.

The pseudo-second-order model is represented as follows [7-11].

$$
\frac{t}{q_{t}}=\frac{1}{k_{2} q_{e}^{2}}+\frac{t}{q_{e}}
$$

where $\mathrm{k}_{2}$ is the second-order reaction rate constant.

\section{Factors Affecting Adsorption}

For a given adsorbent material and adsorbate, the following are the factors affecting batch adsorption.

\subsection{Initial concentration of adsorbate.}

If the initial concentration of adsorbate is high, then the driving force for adsorption is more, and adsorption is fast. This effect is expected up to a certain maximum concentration of adsorbate corresponding to the adsorption ability of the adsorbent. There is a certain maximum concentration that can be treated for a given adsorbent-adsorbate combination [12-25].

3.2. $p H$.

Adsorption is $\mathrm{pH}$ sensitive process. Depending on the positive or negative charges on adsorbate, optimum $\mathrm{pH}$ is basic, acidic, or neutral. Heavy metals adsorb efficiently at $\mathrm{pH}$ value 
6 to 8 . At very low $\mathrm{pH}$, metal ions compete with $\mathrm{H}^{+}$ions. At a very high $\mathrm{pH}$, the precipitate can be formed. These kinds of reactions and interactions affect the optimum $\mathrm{pH}$ value [12-20].

\subsection{Adsorbent dose.}

With an increase in adsorbent, the surface available for adsorption increases. The adsorption increases up to certain adsorbent dose, beyond which, the effect of the increase in adsorbent amount becomes insignificant. This is due to the inability of adsorbate to reach to the adsorbent surface [20-25].

\subsection{Particle size.}

Smaller particle size corresponds to more surface area for adsorption. However, very small particles can affect the adsorption adversely by forming a slurry. There is an obstacle to the adsorbate particles due to highly dense slurry. So, there is certain optimum particle size, below which the adsorption is adversely affected by a further decrease in the particle size [1525].

\section{Adsorbent Preparation and Activation}

The preparation of adsorbent from low-cost adsorbent has given a boost to research on adsorption preparation from low-cost adsorbents [26-31]. Domestic and agricultural waste can be used for adsorbent preparation [31-35].

Thermal and chemical activation methods can be used for adsorption preparation. General steps in adsorbent preparation are Washing, cutting/size reduction, atmospheric drying, thermal drying, chemical and/or thermal activation [36-40]. Various low-cost materials are used for the preparation of adsorbent for the removal of various pollutants from wastewater [41-45].

Applicability of the adsorbent in industries depends on the adsorption efficiency, regeneration, recovery, and disposal cost of the adsorbent. Desorption studies of the adsorbent are also required before using the adsorbents in pilot plants or industries [46-51]. This review contains insight into investigations carried out to study adsorbent preparation and its characterization for the removal of adsorbates from the solution.

\section{Investigations on Adsorbent Preparation and Characterization}

\subsection{Coconut husk, banana trunk, sago humppas, rice husk, and oil palm.}

Samsuddin used agricultural wastes, namely coconut husk, banana trunk, sago humppas, rice husk, and oil palm for characterization and preparation of adsorbent in his investigation [52]. Pre-treatment using alkali, acid, and oxidizing chemicals disrupt the structure. In the pre-treatment, the properties of the biomass are altered to increase the number of sites. In the case of alkali, pre-treatment, Solvation, and saponification takes place [51]. This results in a decrease in the degree of polymerization. Acid treatment increases porosity and surface area. Low pH after acid treatment is not favorable for adsorption [52].

Okafor et al. used a coconut shell as a starting material for the preparation of bio-sorbent [53]. The adsorption was second order and followed intraparticle diffusion models closely. The data also followed the Freundlich isotherm. 
Ju and Ezuma used Palm Kernel fiber and Coconut husks for chromium removal from synthetic wastewater [54]. They cut the material into small pieces and fibers, washed with hot water to remove moisture. They kept this material in an oven at a temperature of $80^{\circ} \mathrm{Cfor} 24$ hours. Coconut husk adsorbent was better adsorbent with more than 90 percent removal against 84 percent removal of Kernal fiber adsorbent. Coconut husk adsorbent followed Freundlich isotherm indicating multilayer adsorption on heterogeneous sites. Kernal fiber adsorption was a single layer and followed Langmuir adsorption.

Many similar investigations are reported on the application of coconut and groundnut waste for removal of organic pollutants like phenol and inorganic pollutants like heavy metals from wastewater [55-64]

\subsection{Hard shells of apricot stones, bagasse, almond, walnut, hazelnut shells, and almond.}

Soleimani and Kaghazchi used five different adsorbents in their investigation, namely hard shells of apricot stones, bagasse, almond, walnut, and hazelnut shells [65]. The chemicals used in chemical activation are dehydrating agents. These chemicals influence pyrolytic decomposition and inhibit the formation of tar[65].In the preparation of adsorbents, they studied the effect of various parameters like activation time, activation temperature, impregnation ratio on the adsorbent. The study indicated that there is a certain optimum time above which the pores enlarge and even collapse. An increase in temperature decreases the iodine number and carbon yield. Based on these studies, final parameters have to be selected for bulk synthesis of the adsorbent. The values of optimum parameters depend on the starting raw material. Activated carbon prepared from hard shells of apricot stones yielded the best properties.

\subsection{Potato peels.}

Kyzas and Mitropoulos carried out an investigation on the preparation of adsorbent from potato peels by the hydrothermal method [66]. They used potassium hydroxide as an impregnation agent supplemented by the thermal activation method. A pH value of 6 was found to be optimum for lead removal. Further increase in $\mathrm{pH}$ may result in the formation of the precipitate.

The maximum theoretical adsorption capacity was about $215-250 \mathrm{mg} / \mathrm{g}$ at the temperature range of 20 to $40{ }^{\circ} \mathrm{C}$ [66]. The adsorption data fitted in the Langmuir isotherm equation with $\mathrm{R}^{2}$ value above 0.99 .

The use of Banana peels and potato peels for the removal of pollutants from wastewater is the most sought-after research area. Taralgatti investigated adsorbent preparation and removal of copper from wastewater by using these adsorbents [67]. Copper removal above 90 percent was obtained with potato peels by her during the investigation. Adsorbent preparation steps were drying, washing, and again drying in the furnace for two days.

\subsection{Mustered cake.}

The mustered cake was used for the preparation of adsorbent by Singh et al. [68]. This adsorbent was used by them for phenol removal from wastewater. According to them, adsorption characteristics of these adsorbents are due to oxides of various elements and also the presence of silica. They used hydrogen peroxide to oxidize adhered organic matter. Scanning electron microscopy indicated homogeneous structure pores with cylindrical shapes. 
The specific surface area was above $25 \mathrm{~m}^{2} / \mathrm{g}$ [68]. The adsorption followed Langmuir isotherm, indicating monolater adsorption on the finite number of homogeneous sites. The adsorption was a pseudo-second-order.

\subsection{Palm trees, waste cartons, and plastics.}

Activated carbon can be prepared from mixed waste by using carbonization and zinc chloride activation [68]. Alothaman et al. used waste material containing palm trees, waste cartons, and plastics [69]. A three-step preparation process included carbonization, impregnation, and then activation for a specific period. The yield of activated carbon was a function of the amount of zinc chloride and activation temperature [69]. Zinc chloride inhibits the formation of volatile matter, which increases the bulk density. With an increase in temperature, the bulk density decreases due to an increase in the evolution of volatile matter [69].

\subsection{Apple waste.}

Ramdane et al. used the microwave activation method with nitrogen activation of activated carbon. They investigated the activated carbon prepared from apple waste [70]. They observed that microwave radiation temperature and time had a considerable effect on the activation of carbon. An increase in these parameters had an adverse effect on the yield. $800^{\circ} \mathrm{C}$ and 10 minutes were the optimum value of these two parameters. Ultimate and proximate analysis endorsed apple waste as adsorbent material with high lignocellulosic material. The cadmium uptake followed Langmuir isotherm indicating monolayer and homogeneous adsorption. The microwave-assisted phosphoric acid activation method can be used for the preparation of adsorbent from apple waste for adsorption of methylene blue [71]. They carried out a separate analysis of adsorbent obtained from pulp and peel-based waste. For pulp-based adsorbent, there was a 20 percent increase in adsorption for an increase in time from 10 to 15 minutes at lower $\left(550^{\circ} \mathrm{C}\right)$ activation temperature. For higher activation temperature $\left(700^{\circ} \mathrm{C}\right)$ after 12-13 minutes, the adsorption decreases, indicating inactivation of activated sites after 13 minutes [71]. It shows that optimum time decreases with increasing temperature.

\subsection{Dry fruits of acacia.}

Dry fruits of acacia were used for the preparation of activated carbon for fluoride removal from wastewater by Hanumantharao et al. [72]. They used washing and thermal activation. Dilute nitric acid was used for washing. Before washing, the material was washed with distilled water and carbonized at $700^{\circ} \mathrm{C}$ in the furnace. The BET surface area of the adsorbent was more than $700 \mathrm{~m}^{2} / \mathrm{g}$ [72]. They observed that fluoride ion adsorption favored acidic conditions. The adsorbent surface was highly heterogeneous and followed Freundlich isotherm.

\subsection{Banana peels.}

Banana peels were used for the preparation of activated carbon by Chafidz et al. [ 73]. They used zinc chloride impregnation with 3:1 proportion. The resulting adsorbent was able to remove carbon monoxide above 97 volume percent. Banana peels were used for the preparation of biosorbent by Hossain et al. In this process, the banana peels were washed with distilled water and then dried at $105^{\circ} \mathrm{C}$ in an oven for 24 hours [74]. According to their studies, $28 \mathrm{mg}$ 
copper per gram of banana bio sorbent was adsorbed. The banana peel sorbent followed second-order kinetics. It followed both isotherm models, namely Langmuir and Freundlich. The advantage of this process is that it removes the need for high-temperature carbonization and hence saves much energy.

Parlayici and Pehlivan investigated the use of biowaste derived adsorbent for chromium removal [75]. The adsorbents were derived from cranberry kernel shell, rosehip seed shell, and banana peel. In the adsorbent preparation procedure, they isolated and washed cranberry kernel shells, rosehip seed shell with water, and then soaked in water. Another material banana peel was washed with water. After that, all three adsorbent materials were kept in the furnace for one day. FT-IR analysis confirmed the existence of many functional groups on the adsorbent surface [75]. Adsorption was high at lower $\mathrm{pH}$ values. At lower $\mathrm{pH}$ values, a large number of $\mathrm{H}^{+}$ions are formed. These ions neutralize the hydroxyl group present on the biomass. This causes hindrance to diffusion of positively charged dichromate ions [71-76]. Highly protonated adsorbent surfaces coordinate with the oxyanion present in the solution through electrostatic interaction. At $\mathrm{pH}$ value below 2, the removal decreases due to the formation of more polymerized chromium oxide species [73].

Fruit peels of banana, orange, citrus, lemon, and jackfruit, were used the removal of lead from wastewater by Pathak et al. [76]. They studied surface, physical and chemical characteristics. Analysis indicated high (85\%) volatile content in fruit peeks. The moisture content after washing and drying was about 5-8 \%. Porosity was in the range of $40 \%$ to $60 \%$ [76].

\subsection{Ram horn, plantain peels, sugar cane chaff, car tire, and ram hair.}

Nwufo et al. investigated various waste materials, namely Ram horn, plantain peels, Sugar cane chaff, Car tire, and Ram hair for preparation of bio sorbent [77]. These materials were carbonized at $200^{\circ}$ to $350^{\circ} \mathrm{C}$ and then activated with $1 \mathrm{~N}$ hydrochloric acid. According to this study, the adsorption was monolayer, and the results were in agreement with Langmuir isotherm.

\subsection{Datestone.}

Ahmida et al., in their work, used date stone as a starting material for adsorbent preparation [78]. They prepared adsorbent from the date stones at three different temperatures, 300,500 , and $700^{\circ} \mathrm{C}$. They studied the effect on nickel removal by the adsorbent. According to these studies, the adsorbent activated with sodium hydroxide was more effective than the adsorbents activated by sodium chloride and nitric acid. This research also indicated that the chemical activation method was a better option than thermal activation for these types of the adsorbent. This method exhibited changes in the surface functional groups. Also, good development of the porous structure and low activation temperature were other advantages of the chemical activation [78].

\subsection{An eggshell-anthill composite.}

An eggshell-anthill composite (EAC) was used for adsorbent preparation by Yusuff [79]. In his work, he investigated EAC preparation conditions, namely an activation temperature, an activation time, and an eggshell/anthill mass ratio) on the nickel ions uptake. 
They carried out equilibrium studies for this solid, liquid adsorption process. Of all the affecting parameters, activation temperature had a significant effect on the equilibrium [79].

\subsection{Olive waste.}

Physical and chemical activation methods were used for the preparation of adsorbent from Olive waste by Enaime et al. [80]. Olive mill solid waste was impregnated into olive mill wastewater. They used potassium hydroxide and nitric acid as activating agents. This investigation indicated that samples activated by potassium hydroxide show a higher surface area followed by the adsorbent prepared by physical activation. Almost all the adsorbents prepared by physical and chemical activation followed Freundlich isotherm with $\mathrm{R}^{2}$ value above 0.93. Also, adsorption of Indigo carmine on the adsorbents followed second-order kinetics.

\subsection{Orange juice waste.}

Cerium and lanthanum metal ion loaded phosphorylated orange juice waste was found to be very effective for fluoride removal by Ghimire [81]. He dried the waste at $30^{\circ} \mathrm{C}$ for three days. Then they phosphorylated the waste to convert the carboxyl group to phosphate groups.

\subsection{Palm date pits.}

Palm date pits were used as a source of low-cost adsorbents by Esmael et al. [82]. They used this material for adsorption of three heavy metals, copper, hexavalent chromium, and iron. They found that particle size of $0.5-0.8 \mathrm{~mm}$ was optimum for adsorption. Optimum $\mathrm{pH}$ was 47. They obtained a removal efficiency of 90 percent for these adsorbates.

\subsection{Paper industry waste.}

Paper industry waste contains organic matter and calcium compounds. Mensez et al. investigated de-inking paper sludge from recycled paper-press manufacturing (HP) and other organic sludge from eucalyptus virgin pulp mill (RT) [83]. Inorganic content was more in deinking paper sludge adsorbent. HP leads to mesoporous material, whereas RT leads to highly microporous adsorbents. Higher copper removal was obtained by HP. Cation exchange leads to heavy metal removal.

Tanaka prepared adsorbent for cadmium removal from wastewater from solid waste of paper industry [84]. They dried and treated the sludge at $950{ }^{\circ} \mathrm{C}$ to form sludge carbon. They washed this carbon with distilled water and then again dried it at $100{ }^{\circ} \mathrm{C}$ for 24 hours to remove moisture. Their study indicates that cadmium ions precipitate at $\mathrm{pH} 8$. Hence $\mathrm{pH}$ values higher than 8 are not favorable for cadmium removal. At very low $\mathrm{pH}$, the hydrogen ions compete with metal ions. Hence $\mathrm{pH}$ value less than 2 affects the removal adversely. $\mathrm{pH}$ value near 6 favors adsorptions. Langmuir equation explained the equilibrium.

Lead removal by using paper waste-derived adsorbent was studied by Hong et al. [85]. They used waste from the newspaper industry and white paper industry waste. Their study indicated that Langmuir isotherm was followed by solute uptake. According to these studies, carbonate precipitation on the adsorbent surface due to the dissolution of $\mathrm{CaCO}_{3}$ resulted in $\mathrm{Pb}$ (II) removal. 


\subsection{Pineapple waste adsorbent.}

Yamuna and Kamraj investigated adsorptive properties of pineapple seed adsorbent with methylene blue as an adsorbate [86]. They treated dried pineapple shells with sulfuric acid and washed with distilled water. It was then dried in a Muffle furnace at $300^{\circ} \mathrm{C}$ for $3 \mathrm{hrs}$. The percentage of adsorption increased with an increase in $\mathrm{pH}$. This may be because of the attraction between hydroxide and metal ions. Pineapple waste was acidic with pH of 5.7 [86].

\subsection{Rice waste.}

The use of rice as a starting material for adsorbent preparation has been done by a vast number of researchers for the removal of impurities from wastewater [66-96]. The adsorbent preparation by chemical activation method includes drying, crushing, and carbonization [ 97]. For chemical activation of rice husk adsorbent, nitric acid and hydrogen peroxide can be used for activation. Carbonization at around $1000^{\circ} \mathrm{C}$ can be done to obtain activated carbon from the rice husk. Rice husk can be combined with other agricultural waste material for obtaining better results $[97,98]$. Nitrogen adsorption study confirms high surface area (above $500 \mathrm{~g} / \mathrm{m}^{2}$ ) of rice husk-based adsorbent. , The removal of methylene blue follows Langmuir isotherm [98].

\subsection{Sewage sludge.}

Treating waste using waste is the principle in the utilization of waste material for the synthesis of a low-cost adsorbent. Sewage sludge can be used for the preparation of adsorbent. This adsorbent was found to be effective for the adsorption of phenol from wastewater [99]. Steps involved in the preparation of adsorbent were Drying, chemical activation with hydrochloric acid, and thermal treatment at $650{ }^{\circ} \mathrm{C}$. Freundlich isotherm and second-order model described the adsorption process.

\subsection{Sunflower waste.}

Waste biomass of sunflower can be used as a starting material for adsorbent preparation [100]. Sunflower head carbon and Sunflower stem carbon can be used for the removal of cadmium from water. As with many other investigations, the solute uptake followed Freundlich isotherm and second-order kinetics.

\subsection{Tea waste.}

Tea waste was used for the removal of phenol from wastewater by Girish et al. [101]. The surface area of $135 \mathrm{~g} / \mathrm{m}^{2}$, was comparable with other different agricultural adsorbents [102, 103]. Sulphuric acid activation is effective for improving the adsorbent properties [101-103]. Sahu et al. used tea waste from tea stalls for adsorbent preparation and used the adsorbent for heavy metal removal [103]. Adsorption efficiency was maximum for lead removal.

\subsection{Watermelon, corn peel waste, stink bean peel powder.}

Kanthasamy et al. used the powder of watermelon peel and corn peel for adsorbent preparation[104]. They used these adsorbents for the removal of dyes from wastewater. They observed that the maximum removal in batch studies occurred at a $\mathrm{pH}$ value of 3 . The adsorption followed Temkin isotherm and second-order kinetics. The watermelon peel powder was found to be better adsorbent with 49 percent color removal against 19 percent color 
removal by corn peel. Similar experiments were carried out by Anuar et al. for the removal of dyes by using stink peel power[105]. They observed that the adsorption followed Freundlich isotherm and second-order kinetics.

\section{Conclusions}

Many investigations are reported on adsorbent preparation from waste material. Adsorbent preparation from agricultural waste is one of the most widely investigated research areas. Batch studies indicated that the optimum values of initial concentration, $\mathrm{pH}$, adsorbent dosage, and particle size for a solute in a given solvent depend on the nature of adsorbent. Many investigations have been reported on the use of the novel adsorbents like ponkan mandarin, jackfruit, peanut peels, coir pitch, and cork waste [106-113]. The solute uptake by adsorption follows Langmuir or Freundlich isotherm depending on the nature of adsorption, homogeneity of the surface, and active sites. Novel adsorbents derived from sewage sludge, tea waste, an eggshell-anthill composite, ram horn, plantain peels, sugar cane chaff, car tire, and ram hair have shown promising results and can be used after detailed studies on their use in continuous contact equipment.

Optimization of the activation method can reduce time and energy. The use of chemical and thermal activation method depends on raw material composition and temperature required for activation. In most of the investigation, the temperature is optimized after conducting activation experiments at different temperatures. Various new technologies and materials are being explored to reduce treatment costs and increase the effectiveness of pollution control methods. The use of nanoparticles and nanomaterials is also a promising area of investigation in pollution control and environmental engineering[114].

\section{Funding}

There is no external funding involved in the preparation of this review article.

\section{Acknowledgments}

The author is thankful to the authorities of the affiliating institute for support and encouragement.

\section{Conflicts of Interest}

The authors declare no conflict of interest.

\section{References}

1. Treybal, R. E. Adsorption and Ion Exchange. Mass Transfer Operations, Edition 3, McGraw Hill Book Series 1981; pp.565-682.

2. Liming, Y.; Lixia, Y.; Lin, D.; Fang, D.; Xu-Biao, L.; Sheng-Lian L. Principles for the Application of Nanomaterials in Environmental Pollution Control and Resource Reutilization. In: Nanomaterials for the Removal of Pollutants and Resource Reutilization, Micro and Nano Technologies 2019; pp. 1-23, https://doi.org/10.1016/B978-0-12-814837-2.00001-9.

3. Lingling, L.; Xu-Biao, L; Lin, D.; Sheng-Lian, L. Application of Nanotechnology in the Removal of Heavy Metal From Water, Nanomaterials for the Removal of Pollutants and Resource Reutilization Micro and Nano Technologies 2019, pp. 83-147, https://doi.org/10.1016/B978-0-12-814837-2.00004-4.

4. Mamatha, M.; Aravinda, H.B.; Manjappa, S.; Puttaiah, E.T. Kinetics and Mechanism for Adsorption of Lead in Aqueous and Industrial Effluent from Pongamia pinnata Tree Bark. Journal Of Environmental Science, Toxicology And Food Technology 2012, 2, 1-9, https://doi.org/10.9790/2402-0230109. 
5. Srivastava, V.C.; Mall, I.D.; Mishra, I.M. Equilibrium modelling of single and binary adsorption of cadmium and nickel onto bagasse fly ash. Chemical Engineering Journal 2006, 117, 79-91, https://doi.org/10.1016/j.cej.2005.11.021.

6. Visa, M.; Duta, A. Cadmium and Nickel Removal from Wastewater using Modified Fly Ash: Thermodynamic and Kinetic Study. Scientific Study and Research 2008, 9, 7377.

7. Moreno-Castilla, C.; Fontecha-Cámara, M. A; Álvarez-Merino, M. A.; López-Ramón, M. V.; CarrascoMarín, F. Activated carbon cloth as adsorbent and oxidation catalyst for the removal of amitrole from aqueous solution. Adsorption 2010, 17, pp.413-419. https://doi.org/10.1007/s10450-010-9270-x.

8. Stavropoulos, G.G.; Zabaniotou, A.A. Production and characterization of activated carbons from olive-seed waste residue. Microporous and Mesoporous Materials 2005, 82, 79-85, https://doi.org/10.1016/j.micromeso.2005.03.009.

9. Abdel-Raouf, M.S.; Abdul-Raheim, A.R.M. Removal of Heavy Metals from Industrial Waste Water by Biomass-Based Materials: A Review. J Pollut Eff Cont 2017, 5, 1-13, https://doi.org/10.4172/23754397.1000180.

10. Saka, C.; Şahin, Ö.; Küçük, M.M. Applications on agricultural and forest waste adsorbents for the removal of lead (II) from contaminated waters. International Journal of Environmental Science and Technology 2012, 9, 379-394, https://doi.org/10.1007/s13762-012-0041-y.

11. Gupta, S.; Kumar, D.; Gaur, J.P. Kinetic and isotherm modeling of lead(II) sorption onto some waste plant materials. Chemical Engineering Journal 2009, 148, 226-233, https://doi.org/10.1016/j.cej.2008.08.019.

12. Kulkarni, S.J.; Kaware, J.P. Modeling for Packed Bed Phenol Removal by Low Cost Adsorbent Prepared from Rice Husk. Sci. Revs. Chem. Commun. 2016, 6, 1-11.

13. Kulkarni, S.J.; Goswami, A.K. Isotherm, Kinetics and Trickling Flow Studies for Removal of Chromium from Synthetic Effluent by using Mixed Fruit Peels (MFP). International Journal of Innovative Technology and Exploring Engineering 2019, 8, 430-432.

14. Kulkarni, S.J. Effect of Presence of Other Heavy Metals on Removal of Cadmium by Low Cost Adsorbents. International Journal of Latest Engineering and Management Research 2017, 2(9), pp. 15-20. http://www.ijlemr.com/papers/volume2-issue9/15-IJLEMR-22449.pdf

15. Shahlaa, E.; Ebrahim, Modeling the Removal of Phenol by Natural Zeolitein Batch and Continuous Adsorption Systems. J. Babylon University/ Engg. Sci. 2013, 21, 249-262.

16. Karunarathnea, H. D. S. S.; Amarasinghea, B. M. W. P. K. Fixed Bed Adsorption Column Studies for the Removal of Aqueous Phenol from Activated Carbon Prepared from Sugarcane Bagasse. Energy Procedia 2013, 34, 83-90, https://doi.org/10.1016/j.egypro.2013.06.736.

17. Kulkarni, S.J. Low Cost Agricultural Waste Adsorbent for COD Removal: Preliminary Investigation. International Journal of Scientific Research in Chemistry 2017, 2, 13-15.

18. Ojha, P.; Rathilal, S.; Singh, K. Modified Coconut Fiber Used as Adsorbent for the removal of 2chlorophenol and 2, 4, 6-trichlorophenol from Aqueous Solution. South African J. Chem. Engg. 2014, 19, 121.

19. Kulkarni, S.J.; Bhole, L.; Rampure, M. Packed Bed Studies for Iron and Chromium Removal by Low Cost Adsorbents. International Journal of Research \& Review 2016, 75, 75-77.

20. Jadhav, D.N.; Vanjara, A.K. Removal of Phenol from Wastewater using Sawdust, Polymerized Sawdust and Sawdust Carbon. Indian J. Chem. Technol. 2004, 1, 35-41.

21. Kulkarni, S.J.; Joshi, M.; More, N. Removal of Acetic Acid from Wastewater by Groundnut Shell and Coconut Shell Adsorbents. International Journal of Research and Review 2016, 3, 71-74.

22. Kulkarni, S.J. Solute Uptake, Kinetic and Isotherm Studies for Copper Removal: A Review. International Journal of Research 2015, 2, 718-725.

23. Kumar, S.; Rajmohan B., Mohanty, K.; Meikap, B. C. Characterization of Activated Carbon Prepared from Tamarind Wood for Wastewater Treatment. International Journal on Environmental Engineering 2010, 2, 290-302, https://doi.org/10.1504/IJEE.2010.029836.

24. Kulkarni, S.J.; Joshi, M.; More, N. Acetic Acid Adsorption on Rice Husk Adsorbent. International Journal of Science \& Healthcare Research 2016, 1, 18-21.

25. Padmapriya, G.; Murugesan, A.G. Phytoremediation of various heavy metals $(\mathrm{Cu}, \mathrm{Pb}$ and $\mathrm{Hg})$ from aqueous solution using water hyacinth and its toxicity on plants. International Journal of Environmental Biology 2012, 2, 97-103.

26. Moreno-Castilla, C.; Fontecha-Cámara, M.A.; Álvarez-Merino, M.A.; López-Ramón, M.V.; CarrascoMarín, F. Activated carbon cloth as adsorbent and oxidation catalyst for the removal of amitrole from aqueous solution. Adsorption 2011, 17, 413-419, https://doi.org/10.1007/s10450-010-9270-x.

27. Saleem, J.; Shahid, U.B.; Hijab, M.; Mackey, H.; McKay, G. Production and applications of activated carbons as adsorbents from olive stones. Biomass Conversion and Biorefinery 2019, 9, 775-802, https://doi.org/10.1007/s13399-019-00473-7.

28. Azimi, A.; Azari, A.; Rezakazemi, M.; Ansarpour, M. Removal of Heavy Metals from Industrial Wastewaters: A Review. ChemBioEng Reviews 2017, 4, 37-59, https://doi.org/10.1002/cben.201600010.

29. Kaushal, A.; Singk, S.K. Adsorption phenomenon and its application in removal of lead from waste water: a review. Int J Hydro. 2017, 1, 38-47, https://doi.org/10.15406/ijh.2017.01.00008. 
30. Khan, T.A.; Mukhlif, A.A.; Khan, E.A.; Sharma, D.K. Isotherm and kinetics modeling of Pb(II) and Cd(II) adsorptive uptake from aqueous solution by chemically modified green algal biomass. Modeling Earth Systems and Environment 2016, 2, https://doi.org/10.1007/s40808-016-0157-z.

31. Tharani, A.; Ravishankar; Harish; Mageshkumar, P.; Ramesh, S. Comparative Study on Removal Of Heavy Metals From Textile Industry Wastewater Using Various Adsorbent. International Journal of Advanced Science and Engineering Research 2017, 2, 12-22.

32. Kulkarni, S.J.; Kaware, J.P. Removal of Cadmium from Wastewater by Groundnut Shell Adsorbent-Batch and Column Studies. International Journal of Chemical Engineering Research 2014, 6, 27-37.

33. Yadav, S.;Tyagi, D.K.;Yadav,O.P.Equilibrium and Kinetic Studies on Adsorption of Aniline Blue from Aq ueous Solution onto Rice Husk Carbon. International Journal of Chemistry Research 2011, 2, 59-64.

34. Kulkarni, S.J.; Kaware, J.P. Adsorption for Cadmium Removal from Effluent- A Review. International Journal of Science, Engineering and Technology Research 2013, 2, 1840-1844.

35. Kulkarni, S.J.; Kaware, J.P. Batch and Column Studies for Phenol Removal from Wastewater Using Low Cost Adsorbent. Int. J. Research in Chemistry and Environment 2014, 4, 127-132.

36. Yildiz, S. Kinetic And Isotherm Analysis Of $\mathrm{Cu}(\mathrm{Ii})$ Adsorption Onto Almond Shell (Prunus Dulcis). Ecol. Chem Eng S. 2017, 24, 87-106, https://doi.org/10.1515/eces-2017-0007.

37. Sundaram, M.; Sivakumar, S. Use of indian almond shell waste and groundnut shell waste for the removal of azure a dye from aqueous solution. Journal of Chemical and Pharmaceutical Research 2012, 4, 2047 2054.

38. Idris, S.; Iyaka, Y.A.; Dauda, B.E.N.; Ndamitso, M.M. ; Umar, M.T. Kinetic Study of Utilizing Groundnut Shell as an Adsorbent in Removing Chromium and Nickel from Dye Effluent. American Chemical Science Journal 2012, 2, 12-24, https://doi.org/10.9734/ACSJ\%2F2012\%2F908.

39. Gonçalves, M.; Guerreiro, M.C.; Ramos, P.H.; Oliveira L.C.; Sapag, K. Activated carbon prepared from coffee pulp: potential adsorbent of organic contaminants in aqueous solution. Water Science \& Technology 2013, 68, 1085-1090, https://doi.org/10.2166/wst.2013.349.

40. Gonçalves, M.; Guerreiro, M.C.; Oliveira, L.C.A.; Solar, C.; Nazarro, M.; Sapag, K. Micro Mesoporous Activated Carbon from Coffee Husk as Biomass Waste for Environmental Applications. Waste and biomass Valorization 2013, 4, 395-400, https://doi.org/10.1007/s12649-012-9163-1.

41. Boudrahem, F.; Aissani-Benissad, F.; Aït-Amar, H. Batch sorption dynamics and equilibrium for the removal of lead ions from aqueous phase using activated carbon developed from coffee residue activated with zinc chloride. Journal of Environmental Management 2009, 90, 3031-3039,. https://doi.org/10.1016/j.jenvman.2009.04.005.

42. Kulkarni, S.J.; Dhokpande, S.R.; Kaware, J.P. Studies on Fly ash As an Adsorbent for Removal of Various Pollutants from Wastewater. International Journal of Engineering Research and Technology 2013, 2, 11901195.

43. Kulkarni, S.J. Removal Of Organic Matter From Domestic Waste Water By Adsorption. International Journal of Science, Engineering and Technology Research 2013, 2, 1836-1840.

44. Jayaram, K.; Prasad, M.N.V. Removal of $\mathrm{Pb}(\mathrm{II})$ from aqueous solution by seed powder of Prosopis juliflora DC. Journal of Hazardous Materials 2009, 169, 991-997, https://doi.org/10.1016/j.jhazmat.2009.04.048.

45. Kulkarni, S.J.; Patil, S.V.; Bhalerao, Y.P. Fly ash Adsorption Studies for Organic Matter Removal Accompanying Increase in Dissolved Oxygen. International Journal of Chemical Engineering Applications 2011, 2, 434-438, https://doi.org/10.7763/IJCEA.2011.V2.147.

46. Kulkarni, S.J.; Kaware, J.P. Desorption studies for low cost adsorbents. International Journal of Chemical Studies 2015, 3, 38-41.

47. Goncharenko, Y.V.; Gorobets, V.; Govorishev, A.; Zotov, S.; Golovko, M., Kivva, F. Equipment for Adsorbent Regeneration with Application of High-Power UHF Electromagnetic Field. 21st International Conference on Electricity Distribution, Frankfurt, 6-9 June 2011; pp. 231-232.

48. Comans, R.N.J. Adsorption, desorption and isotopic exchange of cadmium on illite: evidence for complete reversibility. Water Research 1987, 21, 1573-1576, https://doi.org/10.1016/0043-1354(87)90143-6.

49. Lei, T.; Li, S.-J.; Jiang, F.; Ren, Z.-X.; Wang, L.-L.; Yang, X.-J.; Tang, L.-H.; Wang, S.-X. Adsorption of Cadmium Ions from an Aqueous Solution on a Highly Stable Dopamine-Modified Magnetic NanoAdsorbent. Nanoscale Research Letters 2019, 14, 1-17, https://doi.org/10.1186/s11671-019-3154-0.

50. Kulkarni, S.J.; Kaware, J.P. Phenol Desorption from Adsorbent - A Review. International Journal of Engineering Sciences \& Management Research 2015, 2, 5-7.

51. Lata, S.; Singh, P.K.; Samadder, S.R. Regeneration of adsorbents and recovery of heavy metals: a review. International Journal of Environmental Science and Technology 2015, 12, 1461-1478, https://doi.org/10.1007/s13762-014-0714-9.

52. Samsudin, S.N.S.B. Preparation and Characterisation of Treated Agricultural Wastes as Biosorbents, Degree of Bachelor of Science, Supervisor: Dr Sim Siong Fong Resource Chemistry Department. Faculty of Resource Science and Technology University Malaysia Sarawak, 2012.

53. Okafor, O.C.; Okon, P.U.; Daniel, E.F.; Ebenso, E.E. Adsorption Capacity of Coconut (Cocos nucifera L.) Shell for Lead, Copper, Cadmium and Arsenic from Aqueous Solutions. Int. J. Electrochem. Sci. 2012, 7 , 12354- 12369. 
54. Ju; Okoli, Ibe Ezuma, Adsorption Studies of Heavy Metals by Low-Cost Adsorbents. J. Appl. Sci. Environ. Manage. 2014, 18, 443-448.

55. Kulkarni, S.J.; Kaware, J.P. Analysis of Packed Bed Adsorption Column with Low Cost Adsorbent for Cadmium Removal. Int. J. of Thermal \& Environmental Engineering 2015, 9, 17-24.

56. Song, C.; Wu, S.; Cheng, M.; Tao, P.; Shao, M.; Gua, G.; Adsorption Studies of Coconut Shell Carbons Prepared by KOH Activation for Removal of Lead(II) From Aqueous Solutions. Sustainability 2014, 6, 8698, https://doi.org/10.3390/su6010086.

57. Kiran, B.M.; Srikantaswamy, S.; Pallavi , H.V.; Manoj, V.; Tasneem, T. A Study on utilization of groundnut shell as biosorbent for heavy metals removal. J. Environ. Sci. 2013, 2, 173-186.

58. Ajmal, M.; Rao, R. A. K.; Ahmad J.; Ahmad, R. The Use of Testa of Groundnut Shell (Arachis hypogea) for the Adsorption of $\mathrm{Ni}(\mathrm{II})$ from the Aqueous System. Journal of Environ. Science and Engg. 2006, 48, $221-224$.

59. Haldhar, D.; Sahoo, S.; Mishra, P.C. Adsorption of As (III) from Aqueous Solution by Groundnut Shell. Indian Journal Of Applied Research 2014, 4, 270-273.

60. Hashemian, S.; Salari, K.; Salehifar, H.; Yazdi Z.A. Removal of Azo Dyes (Violet B and Violet 5R) from Aqueous Solution Using New Activated Carbon Developed from Orange Peel. Journal of Chemistry 2013, 10, https://doi.org/10.1155/2013/283274.

61. Kulkarni, S.J.; Kaware, J.P. Kinetics of Phenol Uptake from Wastewater by Adsorption in a Fixed Bed. J. Chem. Bio. Phy. Sci. Sec. A. 2014, 4, 3116-3123.

62. Owabor, C.N.; Aluyor, E.O.Application of adsorbent as a novel technique during biodegradation of a polycyclic aromatic hydrocarbon (anthracene). African Journal of Biotechnology 2008, 7, 3321-3325.

63. Qaiser, S.; Saleemi, A.R.; Umar, M. Biosorption of lead (II) and chromium (VI) on groundnut hull: Equilibrium, kinetics and thermodynamics study. Electronic Journal of Biotechnology 2009, 12, 1-17, https://doi.org/10.2225/vol12-issue4-fulltext-6.

64. Kulkarni, S.J. Preparation of Low Cost Adsorbents: A Review. International Journal of Research 2014, 1 , 1689-1694.

65. Soleimani, M.; Kaghazchi T. Agricultural Waste Conversion to Activated Carbon by Chemical Activation with Phosphoric Acid. Chem. Eng. Technol. 2007, 30, 649-654, https://doi.org/10.1002/ceat.200600325.

66. Kyzas, G.Z.; Mitropoulos, A.C.. Zero Cost Agricultural Wastes as Sources for Activated Carbons Synthesis: Lead Ions Removal from Wastewaters. Proceedings 2018, 2, 1-10, https://doi.org/10.3390/proceedings2110652.

67. Taralgatti, P.D. Removal of copper from Waste water by using potato and banana peels as bio-adsorbent. International Journal of Science, Engineering and Technology Research 2016, 5, 3038-3041.

68. Singh, K.; Chandra, B.; Gautam, M.; Development of Inexpensive Adsorbent from Agro-waste for Phenol Adsorption. Journal of Scientific and Industrial Research 2016, 75, 444-451.

69. Alothman, Z. A.; Habila, M.A.; Ali, R. Preparation of Activated Carbon Using the Copyrolysis of Agricultural and Municipal Solid Wastes at a Low Carbonization Temperature. International Conference on Biology, Environment and Chemistry IPCBEE vol.24 (2011) (C) (2011) IACSIT Press, Singapoore, 2011; pp.67-75.

70. Ramdane, N.; Boucheltaa, C.; Marsaa, Z.; Medjrama, M.S.; Magrib, P. Production of activated carbon from apple waste prepared under $\mathrm{N}_{2} /$ microwave. Journal of Chemical and Pharmaceutical Research 2016, 8, 617627.

71. Hesas, R.H.; Arami-Niya, A.; Dauda, W.M.A.W.; Sahu, J.N. Preparation and Characterization of Activated Carbon from Apple Waste by Microwave Assisted Phosphoric Acid Activation: Application in Methylene Blue Adsorption. BioResources 2013, 8, 2950-2966.

72. Hanumantharao, Y.; Kishore, M.; Ravindhranath, K. Preparation and Development of Adsorbent Carbon from Acacia Farnesiana for Defluoridation. International Journal of Plant, Animal and Environmental Sciences 2011, 1, 209-224.

73. Chafidz, A.; Astuti, W.; Hartanto, D.; Mutia, A.; Sari, P. Preparation of activated carbon from banana peel waste for reducing air pollutant from motorcycle muffler. MATEC Web of Conferences 2018, 154, 1-5.

74. Hossain, M.A.; Ngo, H.H.; Guoand W.S.; Nguyen, T.V. Removal of Copper from Water by Adsorption onto Banana Peel as Bioadsorbent. Int. J. of Geomate 2012, 2, 227-234.

75. Parlayici, Ş.; Pehlivan, E. Comparative study of $\mathrm{Cr}(\mathrm{VI})$ removal by bio-waste adsorbents: equilibrium, kinetics, and thermodynamic. Journal of Analytical Science and Technology 2019, 10, 1-8, https://doi.org/10.1186/s40543-019-0175-3.

76. Pathak, P.D.; Mandavgane, S.A.; Kulkarni, B.D. Fruit peel waste: characterization and its potential uses. Current Science 2017, 113, 444-454, https://doi.org/10.18520/cs/v113/i03/444-454.

77. Nwufo, B.T.; Priscila, A.U.; Onche, E.U. Production Of Cost-Effective Adsorbents From Native Materials. International Journal of Chemistry and Materials Research 2014, 2, 30-35.

78. Khadija Ahmida, K.; Mabroka Darmoon, M.; Fatma Al-Tohami, F.; Erhayem, M.; Zidan, M. Effect of Physical and Chemical Preparation on Characteristics of Activated Carbon from Agriculture Solid Waste and their Potential Application. International Conference on Chemical, Civil and Environmental Engineering (CCEE-2015) Istanbul (Turkey) 2015, 83-87, http://dx.doi.org/10.15242/IICBE.C0615015. 
79. Yusuff, A.S. Optimization of The Preparation Conditions of An Eggshell/Anthill Composite Adsorbent Using A Central Composite Design. Journal of Chemical Technology and Metallurgy 2019, 54, 1202-1214.

80. Enaime, G.; Ennaciri, K.; Ounas, A.; Baçaoui, A.; Seffen, M.; Selmi, T.; Yaacoubi, A. Preparation and characterization of activated carbons from olive wastes by physical and chemical activation: Application to Indigo carmine adsorption. J. Mater. Environ. Sci. 2017, 8, 4125-4137.

81. Ghimire, K.N. Effective Removal of Fluoride onto Metal Ions Loaded Orange Waste. J. Nepal Chem. Soc. 2011, 27, 61-66.

82. Esmael, A.I.; Matta, M.E.; Hisham A.; Halim, H.A.; Azziz, F.M.A. Adsorption of Heavy Metals from Industrial Wastewater using Palm Date Pits as Low Cost Adsorbent. International Journal of Engineering and Advanced Technology 2014, 3, 72-76.

83. Mendez, A.; Barriga, S.; Fidalgo, J.M.; Gasco, G. Adsorbent materials from paper industry waste materials and their use in $\mathrm{Cu}$ (II) removal from water. $J$ Hazard Mater. 2009, 165, 736-43, https://doi.org/10.1016/j.jhazmat.2008.10.055.

84. Siswoyo E.; Tanaka, S. Development of Eco-adsorbent Based on Solid Waste of Paper Industry to Adsorb Cadmium Ion in Water. Journal of Clean Energy Technologies 2013, 1, 198-201, https://doi.org/10.7763/JOCET.2013.V1.45.

85. Hong, H.; Kim, J.; Yoon, I.; Yoo, G.; Kim, E.; Ahn J.; Yang J. Preparation of Low-Cost Adsorbents from Paper Industry Wastes and their $\mathrm{Pb}(\mathrm{II})$ Removal Behavior in Water. Separation Science and Technology 2014, 49, 2540-2547, https://doi.org/10.1080/01496395.2014.927487.

86. Yamuna, M.; Kamaraj, M. Pineapple peel waste activated carbon as an adsorbent for the effective removal of methylene blue dye from aqueous solution. 2016, 9, 544-550.

87. Islamuddin, G.; Khalid, M.A.; Ahmad, S.A. Study of eco-friendly agricultural wastes as non-conventional low-cost adsorbents: A review. Ukrainian Journal of Ecology 2019, 9, 68-75.

88. Emenike, P.C.; Omole, D.O.; Ngene, B.U.; Tenebe, I.T. Potentiality of agricultural adsorbent for the sequestering of metal ions from wastewater. Global J. Environ. Sci. Manage. 2016, 2, 411-442, https://doi.org/10.22034/gjesm.2016.02.04.010.

89. Mahanti, C.L.V.V.; Suvarna.Laxmi, G. Removal of Dyes by Using Low Cost Adsorbents Agricultural Wastes and Sand. International Journal of Engineering Research \& Technology 2014, 3, 1749-1760.

90. Pham, T.T., Mai, T.T.T.; Bui, M.Q.; Mai, T.X.; Phan, T.B. Synthesis of adsorbent materials based on polyaniline and agriculture waste by soaking method for removal heavy metal ions from solution. ChemXpress 2014, 3, 1-10.

91. Thomas, B.N.; George, S.C. Production of Activated Carbon from Natural Source. Trends in Green Chemistry 2015, 1, 1-5.

92. Hegazi, H.A. removal of heavy metals from wastewater using agricultural and industrial wastes as adsorbents. HBRC Journal 2013, 9, 276-282, https://doi.org/10.1016/j.hbrcj.2013.08.004. v

93. Zeng, W.; Bai, H. Adsorption/Desorption Behaviors of Acetone over Micro-/Mesoporous SBA-16 Silicas Prepared from Rice Husk Agricultural Waste. Aerosol and Air Quality Research 2016, 16, 2267-2277, https://doi.org/10.4209/aaqr.2016.01.0018.

94. Sharath, D.; Ezana, J.; Shamil, Z. Production of Activated Carbon from Solid Waste Rice Peel (Husk) Using Chemical Activation. Jr. of Industrial Pollution Control 2017, 33, 1132-1139.

95. Brahmaiah, T.; Spurthi, L.; Chandrika K.; Kausalya Chandra, L.; Yashas, S. Removal of Heavy Metals from Waste Water Using Low Cost Adsorbent. International Journal of Trend in Research and Development 2016, 3, 63-70.

96. Das, P.; Goswami, S.; Maity, S. Removal of naphthalene present in synthetic waste water using novel G/GO nano sheet synthesized from rice straw: comparative analysis, isotherm and kinetics. Frontiers in Nanoscience and Nanotechnology 2016, 2, 38-42, https://doi.org/10.15761/FNN.1000107.

97. Gomes, E.; Gupta, R.; Sinha, P. Adsorption Studies on Removal of Chromium from Synthetic Waste Water using Activated Carbon prepared from Rice Husk and Sugarcane Bagasse. International Journal of Engineering Development and Research 2017, 5, 1856-1870.

98. Reddy, P.M.K.; Mahammadunnisa, S.K.; Ramaraju, B.; Sreedhar B.; Subrahmanyam, C.H. Low-cost adsorbents from bio-waste for the removal of dyes from aqueous solution. Environ Sci Pollut Res 2013, 20, 4111-4124, https://doi.org/10.1007/s11356-012-1360-8.

99. Bousbaa, S.; Meniai, A.H. Removal of Phenol from Water by Adsorption onto Sewage Sludge Based Adsorbent. Chemical Engineering Transactions 2014, 40, 235-240, https://doi.org/10.3303/CET1440040.

100. Jain, M.; Garg, V.K.; Garg, U.K.; Kadirvelu, K.; Sillanpaa, M. Cadmium Removal from Wastewater using Carbonaceous Adsorbents Prepared from Sunflower Waste. Int. J. Environ. Res. 2015, 9, 1079-1088, https://doi.org/10.22059/IJER.2015.995.

101. Girish, C.R.; Singh, P.; Goyal, A.K. Removal of Phenol from Wastewater Using tea waste and optimization of conditions using response surface methodology. International Journal of Applied Engineering Research 2017, 12, 3857-3863.

102. Wankhade, A.A.; Ganvir, V.N. Preparation of Low Cost Activated Carbon from Tea Waste using Sulphuric Acid as Activating Agent. International Research Journal of Environment Sciences 2013, 2, 53-55. 
103. Sahu, A.; Chatterjee Mitra, J. Preparation of Thermo-Modified Tea waste and Its Use to Study the Heavy Metal Adsorption from Waste Water. IOSR Journal of Applied Chemistry 2018, 11, 40-46.

104. Kanthasamy, S.; Hadibarata, T.; Hidayat, T.; Alamri, S.A.; Al-Ghamdi, A.A. adsorption of azo and anthraquinone dye by using watermelon peel powder and corn peel powder: equilibrium and kinetic studies. Biointerface Research in Applied Chemistry 2020, 10, 4706-4713. https://doi.org/10.33263/BRIAC101.706713.

105. Anuar, F.I.; Hadibarata, T.; Syafrudin, M.; Fona, Z. Removal of Procion Red MX- 5B from aqueous solution by adsorption on Parkia speciosa (stink bean) peel powder. Biointerface Research in Applied Chemistry 2020, 10, 4774-4779. https://doi.org/10.33263/BRIAC101.774779.

106. Bolat, F.; Govori, S.; Haziri, A.; Spahiu, A.; Faiku, F. Used Tea Waste Adsorption for Removal of Phenol from Synthetic and Kosovo Industrial Waste Water. J. Int. Environmental Application \& Science 2010, 5, 63-67.

107. Gundogdu, A.; Duran, C.; Senturk, H.B.; Soylak, M.; Ozdes, D.; Serencam, H.; Imamoglu, M. Adsorption Of Phenol From Aqueous Solution On A Low-Cost Activated Carbon Produced From Tea Industry Waste: Equilibrium, Kinetic, and Thermodynamic Study. J. Chem. Eng. Data 2012, 57, 2733-2743, https://doi.org/10.1021/je300597u.

108. Kazmi, M.; Saleemi, A.; Feroze, N.; Yaqoob, A.; Ahmad, S. Removal of Phenol from Wastewater Using Activated Waste Tea Leaves. Polish Journal of Chemical Technology 2013, 15, 1-6, https://doi.org/10.2478/pjct-2013-0016.

109. Pavan, F.A.; Lima, I.S.; Lima, É.C.; Airoldi, C.; Gushikem, Y. Use of Ponkan mandarin peels as biosorbent for toxic metals uptake from aqueous solutions. Journal of Hazardous Materials 2006, 137, 527-533, https://doi.org/10.1016/j.jhazmat.2006.02.025.

110. Prahas, D.; Kartika, Y.; Indraswati, N.; Ismadji, S. Activated carbon from jackfruit peel waste by H3PO4 chemical activation: Pore structure and surface chemistry characterization. Chemical Engineering Journal 2008, 140, 32-42, https://doi.org/10.1016/j.cej.2007.08.032.

111. Namasivayam, C.; Kavitha, D. Adsorptive removal of 2,4- dichlorophenol by low-cost coir pith carbon. J. Hazard. Mater.2003, 98, 257-274.

112. Periasamy, K.; Namasivayam, C. Removal of copper (II) by adsorption onto peanut hull carbon from water and copper plating industry wastewater. Chemosphere 1996, 32, 769-789, https://doi.org/10.1016/00456535(95)00332-0.

113. Mourao, P.A.M.; Carrott, P.J.M.; Ribeiro Carrott, M.M.L. Application of different equations to adsorption isotherms of phenolic compounds on activated carbons prepared from cork. Carbon 2006, 44, 2422-2429, https://doi.org/10.1016/j.carbon.2006.05.015.

114. Narasaiah, B.P.; Mandal, B.K. Bio-fabricated $\mathrm{CuO}$ NPs as green catalyst towards remediation of environmental pollutants. Letters in Applied NanoBioScience 2019, 8, 597-603. https://doi.org/10.33263/LIANBS83.597603. 